\title{
Percent Recovered Normalized by Surface Area
}

National Cancer Institute

\section{Source}

National Cancer Institute. Percent Recovered Normalized by Surface Area. NCI

Thesaurus. Code C92415.

The percentage of the dose that is recovered from the specimen type, from dosing to end of the current collection interval divided by the surface area. 